\title{
In-between forgotten spaces in Palestinian cities: the twin cities of Ramallah and Al-Bireh as a case study
}

\author{
L. Najjar \& S. Ghadban \\ Department of Architectural Engineering, Birzeit University, Palestine
}

\begin{abstract}
Huge numbers of leftover and ignored spaces emerged in cities after the fast growth and urban development in the last decades that negatively affect the overall cities environment and the quality of cities open spaces in developed and developing countries, yet they offer great opportunity to enhance the quality of the urban spaces. In Palestine, the problem of such spaces is evident in its cities in general and in the twin cities of Ramallah and Al-Bireh in particular. In their downtown the phenomenon of leftover and ignored spaces is clearly demonstrated, and they cover a large area of land that was forgotten during the last 6 decades and no concrete action was taken to improve them. This paper is to explore, analyze and discuss these forgotten spaces and to propose a proper improvement framework for their regeneration. To do so, four folds methodology was used based on historical and archival research, theoretical review, fieldwork and interviews with stakeholders.

Keywords: sustainable urban development, leftover spaces, ignored spaces, forgotten spaces, cities regeneration.
\end{abstract}

\section{Introduction}

Every day spaces in cities are important to connect people, their life and activities that are concentrated in these public spaces, since providing a high quality public space for everyday life is a priority [1-4]. Accordingly, space protection is one of the most important components to achieve sustainability in cities, especially on their public open spaces [5-7], considering that the global trend is toward achieving sustainable development in cities while public spaces are one of the most powerful tools to do that [8]. The rapid growth and urban 
development in the last decades affects enormously the quality of the open spaces in the cities of the developed and developing countries. Consequently, a huge number of leftover and ignored spaces emerged in these cities, while these spaces have great potential to enhance the life quality in the cities; and as such; their revitalization will assist in environmental protection, social relations improvement and cities marketing [5, 9, 10]. In the developing countries there is no tangible action towards these spaces; despite that, their cities have an urgent need for providing tangible quality in their public open spaces. Palestine, as one of these countries, has a sufficient number of such spaces concentrated mainly in the downtowns of the main cities and this issue is clearly demonstrated in the twin cities of Ramallah and Al-Bireh, which downtown looks dense and over built, but it contains a great number of empty open spaces. Their urban fabric was affected by several historical turning points causing great number of leftover, neglected spaces that are almost inaccessible, invisible and disregarded by inhabitants. These spaces exploitation in the right way might give added value to the sustainability approach in the downtown. Thus the aim of this paper is to explore these open spaces within the twin cities downtown that will be called later on as in-between forgotten spaces, to propose planning and urban design recommendations to revitalize and integrate these in-between forgotten spaces into the urban fabric of the twin cities and suggest uses that afford the downtown needs. For this purpose the methodology used concentrated on four folds as shown in fig. 1 .

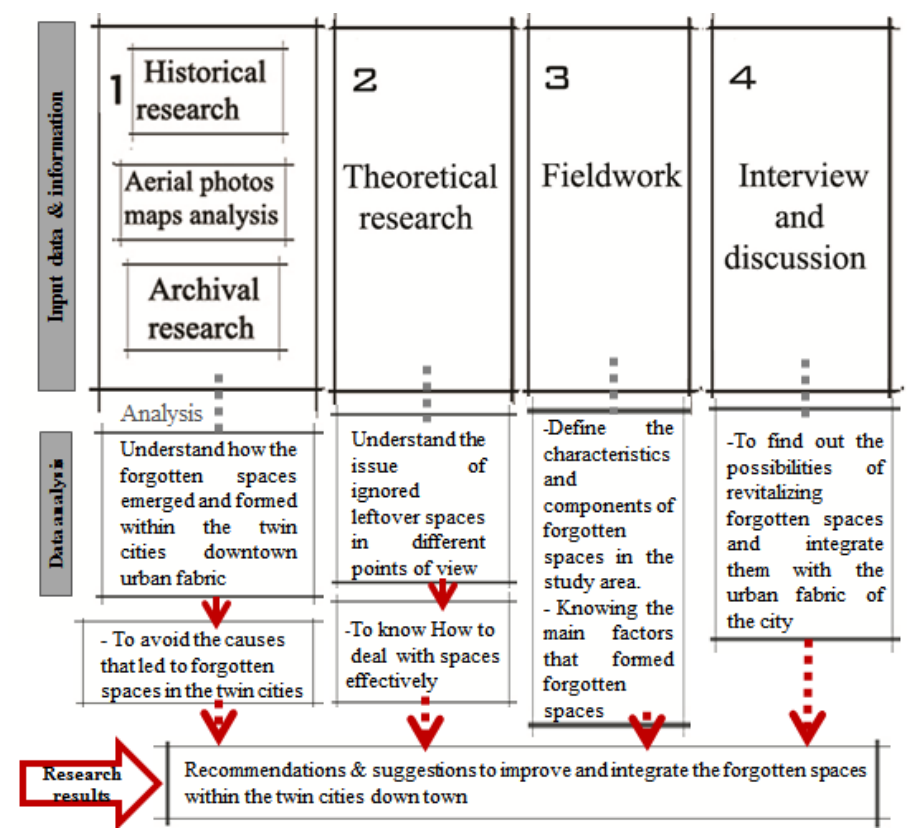

Figure 1: A diagram showing the four fold methodology used in studying and analysing the in-between forgotten spaces in Ramallah and Al-Bireh. 


\section{In-between forgotten spaces definition, characteristics and explanations}

For the purpose of this study the definition used for in- between forgotten spaces is any space enclosed between a number of buildings that is leftover, ignored, and undervalued; they have their negative effect on the environment, the social relations, the image and the identity of the downtown.

Trancik and Lynch were the pioneers to discuss such spaces issue, neglected and leftover spaces. Trancik [11], in his book "Finding lost space", described the badly used lands as "lost spaces" or "antispaces". He defined them as any space that have no shape, no definition, planned incorrectly, hardly measured, undefined, useless or used in a wrong way with low human activity that made it meaningless space, nobody is caring about it and it is unfavorable space. For example, disused waterfronts, unformed hidden lands, leaved train yards, old military lands and obsolete industrial sites are classified as lost spaces. According to Trancik, in cities there is no relation between the buildings and their surroundings, this because of current planning and architecture approaches, while the in-between buildings spaces are occasionally designed. The dominancy of private interests over public interests has raised the problem and the open spaces gradually became privatized. Without solving the conflict between private and public sectors, identification, representation and naming of the spaces, a quality place with high social interaction does not exist in the cities fabric [11, 12]. Lynch [13] in his book "Wasting Away" also discussed this issue as "waste space", as dead, un-used, neglected, empty and dirt. For him, these spaces are a waste of time, of lands and waste of everything. Due to Lynch, the waste of spaces became phenomena $[14,15]$, but they have potential for re-use and relief [16]. Lynch argued that the problem of waste spaces is caused of fixed functions spaces; the solution is by increasing flexibility of spaces to accommodate all time's needs [17]. In the book "Loose Space" two types of loose space discussed, they are: 1) Spaces for specific uses, and 2) Other spaces for unknown functions (leftover and undefined). Loose space is created by people's actions, to reach their needs, still, the streets, land uses variety and ownership issues also contribute in this loose space creation. There is a gap between the human and the space and that causes the death of this space [15]. Leftover spaces usually are located next to the spaces with fixed functions (near the highways under bridges and closed between buildings) [15]. These spaces are difficult to access, have odd shapes and no name. However, they have special characters that provoke artists, architects and urban designer for more creativity [16].

\section{Urban development of the forgotten spaces around Al-Manara Square}

Several turning points affected in the twin cities urban fabric and assisted in the formation of in-between forgotten spaces, these turning points are: the British mandate, the migration of 1948 and 1967 and Oslo Accords. Al-Manara Square 
emerged during the British mandate that started in 1917 at the place, where the road connecting Ramallah and Al-Bireh and that connecting Nablus with Jerusalem intersected. In 1935, an electrical pole was installed there to serve the military checkpoint, which the British Army situated at that place that started being called Al-Manara (Light Tower), fig. 2 [18, 19]. This development caused the growth of the two cities to emerge toward this place, residents started to leave their homes in the old cities of Ramallah and Al-Bireh and move to build new houses near from Al-Manara Square, and the two cities attached to each other at 1961 [20]. This process increased between 1948 and 1985, due to the large number of people who were expelled from their home lands due to the establishment of Israel in 1948 and the Six Days War in 1967. New types of buildings emerged for commercial and mixed uses purposes to meet the society's new needs. Following 1967 until now, almost there is no change happened to the built environment in this area, except some replacements of old buildings with new ones, which didn't affect the conditions of the forgotten spaces fig. 2. Due to this process, the forgotten spaces started to appear around Al-Manara Square as a result of the prevailing at that time building regulations and land ownership system.

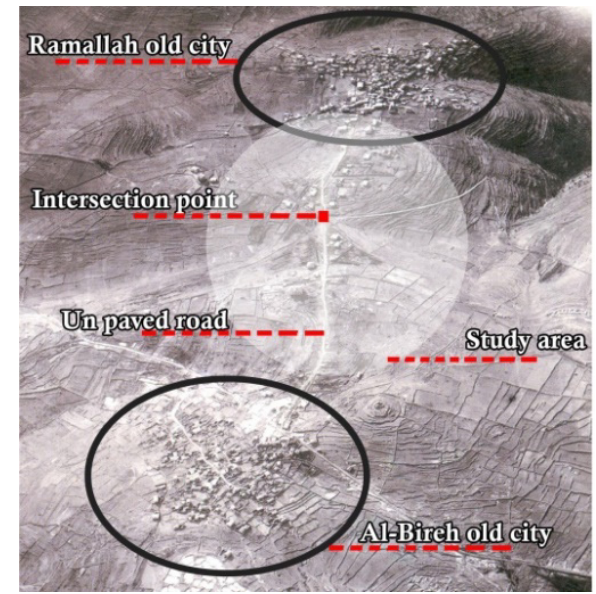

(a)

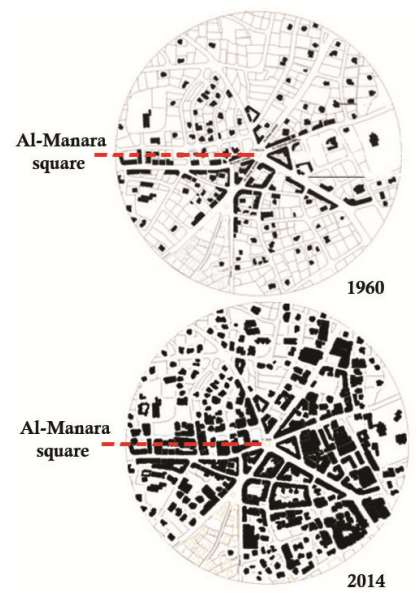

(b)

Figure 2: (a) An aerial photo for the twin cities in 1918, (b) diagrams showing difference of the built environment between the years 1960 and 2014. Reference: Ramallah and Al-Bireh municipalities archive, edited by author.

Thus, the study area is located around Al-Manara Square and the conducted fieldwork covered 502.4 dunums (one dunum is equal to $1000 \mathrm{~m}^{2}$ ), the total area without streets is equal to 421 dunums, while the forgotten spaces occupy 51.1 dunums of the total area. The fieldwork discovered three types of forgotten spaces, they are: 1) Car parking plots located where trees or old buildings were removed and the area used as car parking. Their total area is 24.2 dunums 
(47.4\%) of the overall area of the available forgotten spaces, they are still undervalued spaces and as such, affect negatively the environment and the social relations; 2) Roof tops of the existing low-rise buildings that are currently used as storage and/or garbage areas. They have an area of 8.3 dunums $(16.2 \%)$ of the forgotten spaces area; and 3) In-between forgotten spaces located between existing buildings and cover 18.6 dunums (36.4\%) of the overall area of the available forgotten spaces. The focus of this study was on the in-between forgotten spaces fig. 3 .

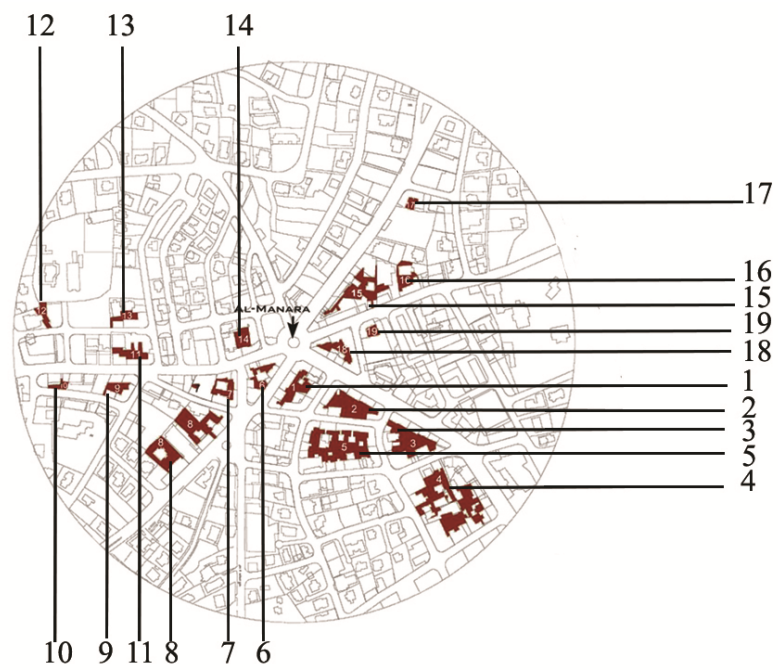

Figure 3: The locations of the in-between forgotten spaces and their numbers.

\section{In-between forgotten spaces}

Each in-between space has its own condition that occurred in response to different variables derived from the space itself or from its surrounding. Within the study area, the buildings around the in-between forgotten spaces are mainly commercial or mixed-use buildings, they are attached to each other, almost creating a barrier between the front space (street elevation) and the back space (backyard space) of the building either visually or physically. The shape, the environment and the components of these spaces are being affected by and they indeed affect their surroundings.

\subsection{Main factors affecting in the formation of the in-between forgotten spaces}

Any phenomenon defined in the urban fabric within specific area happens because of several factors. The conducted fieldwork concludes that the main factors affecting the formation of forgotten spaces in the twin cities downtown are the building-planning regulations and the ownership issues. 


\subsubsection{Buildings-planning Bylaw and regulations}

Building-planning Bylaw contains a set of provisions to control the urban development, and some of these provisions are related to the building design and complexity and thus have a direct impact on the formation of the forgotten spaces. In the new version of the Bylaw from the year 2011, provisions No. 58 and 59 make the violation of building regulations easier, which normally cause urban development confusion and in-between spaces formation. In provision No. 66 , the setbacks for the plots from each zone (residential, commercial, offices, etc.) are defined. The study area is mainly classified as longitudinal commercial zone. The setbacks for this type are zero setbacks for the first 14 meters depth from the street and then a setback of 4 meters should be provided from both sides fig. 4(a). These means the front elevations of the buildings will be attached to each other for $14 \mathrm{~m}$ depth, forming the street's elevation and create open spaces in the backyard of the buildings that become abandoned at a later stage fig. 4(b). In addition, to that, in the building bylaw all articles related to the design are mainly considering the building design in term of colour, height, ventilation system and number of parking, but there is no regulations that take into consideration how to integrate the buildings and the spaces around them, either from the street side or at the backside, such as: how to access these spaces, how to use them, how to prepare a landscape design for them and what kind of greenery must be used there.

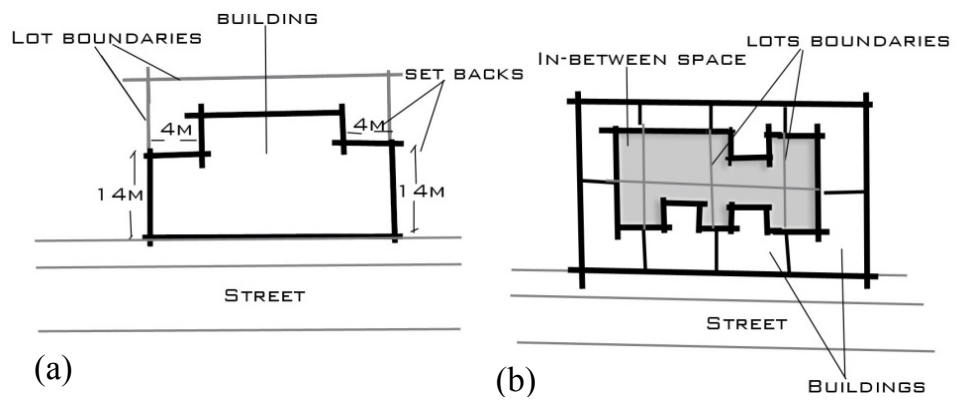

Figure 4: Illustrations showing how the building-planning regulations produce in-between forgotten spaces: (a) an illustration showing the method of setbacking of the buildings, mainly in the longitudinal commercial zone; (b) other illustration showing how the space become enclosed behind the buildings as a result of zero meters setback from the street side.

\subsubsection{Ownership issue}

The ownership is found also as an important issue that affects the urban fabric and the creation of the in-between spaces. In Palestine, land lots are commonly private property, they are inherited and as such, these lots increase in number through time. This increase in the number of owners causes fragmentation of land lots dividing them into smaller pieces. This means more land lots, more buildings, and less open spaces. For example, in space No. 15 fig. 5. 
Accordingly, the area was fragmented into smaller lots, their shape changed and that affects the design of the buildings established on them. While the building regulations are the same regardless of the size of the lot, there is a relation between the number of owners of the in-between space and its quality. In case of single ownership, the owner of this space will be more aware and positive toward any proposal of development and maintenance, but in the case of multi ownership the control of these lots becomes more complicated.
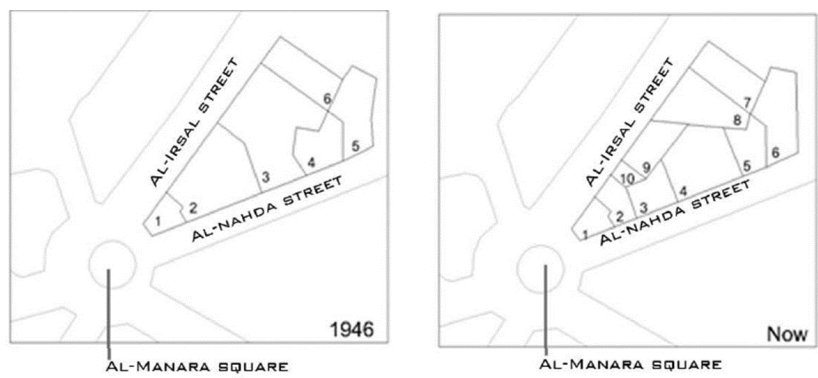

Figure 5: An illustration showing the new ownership status in the time being in space No. 15, where the number of owners increased from 6 owners in 1946 into 10 owners nowadays. Reference: Ramallah municipality archive, edited by author.

\subsection{Components of the in-between forgotten spaces}

Following the fieldwork and for the analysis of the in-between spaces, a set of components was defined considering the surrounding built environment complexity and design, they are:

\subsubsection{Accessibility}

The in-between forgotten spaces in the study area have various accessibility statuses. Thirteen spaces of the nineteen available spaces have at least one direct access from the street, two spaces have direct access from the street but they are closed with a door like spaces No. $15 \& 19$, but the rest four of the spaces have access from the surrounding buildings (No. 14, 7, 5 and 2). Nevertheless, people (downtown visitors) are not aware of these spaces and rarely have access to them. Table 1 shows which space is accessible and which is not. Usually, the ground floors of the buildings in the study area have an access to the backyard, but most of the time this access is closed. Staircase usually is the main access from the building to the backyard, but the owners are renting this space (illegally) to get more financial benefit and to hinder any access to the backyard. Thus, the ground floor shops doors that lead to the backyard are also closed and their renters use this area for displaying their goods.

\subsubsection{Visibility}

Almost all the in-between forgotten spaces in the study area are only visible from the windows and corridors of the surrounding buildings. Most of them lack 
visibility from the street side, except eight spaces of the nineteen are visible from the street, they are spaces No. 2, 3, 6, 8, 9, 10, 12 and 17. In space No. 15, open spaces are decreased through time, new buildings are erected on the open spaces from more sides and that makes it by time totally occupied by buildings (inaccessible and invisible from the street side). Despite that, some spaces are visible from the street but their access is invisible as the case with space No. 17 (Table 1).

Table 1: The accessibility and visibility conditions of the in-between forgotten spaces in the study area as defined in fig. 3 .

\begin{tabular}{|c|c|c|c|}
\hline $\begin{array}{l}\text { Space } \\
\text { No. }\end{array}$ & Accessibility Status & $\begin{array}{l}\text { Visibility of } \\
\text { the Access }\end{array}$ & $\begin{array}{l}\text { Visibility } \\
\text { of the Spaces } \\
\text { from the Street }\end{array}$ \\
\hline 1 & Accessible & Visible & Invisible \\
\hline 2 & $\begin{array}{l}\text { Accessible only from surrounding } \\
\text { buildings (not all of them) }\end{array}$ & - & Visible \\
\hline 3 & Accessible & Invisible & Visible \\
\hline 4 & Accessible & Invisible & Invisible \\
\hline 5 & Has access only from other building & Invisible & Invisible \\
\hline 6 & $\begin{array}{l}\text { Divided into two parts, one is completely } \\
\text { accessible but the other part has two } \\
\text { accesses but they are closed by door. }\end{array}$ & Visible & Visible \\
\hline 7 & $\begin{array}{l}\text { Area (1) is accessible from shops only. } \\
\text { Area (2) has access by surrounding } \\
\text { buildings but it is not activated. }\end{array}$ & - & Invisible \\
\hline 8 & Accessible & Visible & Visible \\
\hline 9 & Two accesses & Visible & Visible \\
\hline 10 & Accessible & Visible & Visible \\
\hline 11 & Accessible & Invisible & Invisible \\
\hline 12 & Accessible & Visible & Visible \\
\hline 13 & Accessible & Invisible & Invisible \\
\hline 14 & $\begin{array}{l}\text { Accessible only from surrounding shop } \\
\text { stores }\end{array}$ & - & Invisible \\
\hline 15 & $\begin{array}{l}\text { One access from street but closed by door } \\
\text { and it is accessible from surrounding shops }\end{array}$ & - & Invisible \\
\hline 16 & Accessible & Invisible & Invisible \\
\hline 17 & Accessible & Invisible & Visible \\
\hline 18 & Inaccessible & - & Invisible \\
\hline 19 & $\begin{array}{l}\text { One access from street but closed by door } \\
\text { and it is accessible from surrounding shops }\end{array}$ & - & Invisible \\
\hline
\end{tabular}

\subsubsection{Environmental conditions}

The fieldwork constituted that eleven in-between forgotten spaces have a problem with their environmental conditions, either in ventilation, lighting or hygiene conditions, etc. The rest of the spaces still have a problem, but their environmental situations still better than the others. In spaces No. 15 and 18, in addition to their bad environmental conditions the buildings enclosure makes both spaces to be used as stores, for solid waste drainage and/or for wastewater 
by the surrounding buildings users. These spaces have a negative effect on the environmental conditions and on the image of the area where they are located. The results show that the accessibility has an important role in the environmental condition of the space, as the inaccessible areas have worst environmental conditions than the accessible ones.

\subsubsection{Image and identity}

Most of the in-between spaces look like storage or garbage areas as spaces No. 1 and 18, or are left empty like space No. 19. This makes these spaces have no defined or specific identity, because of the development activities that take place in the in-between forgotten spaces and in their surroundings, which badly affects the spaces shape, environment, accessibility, visibility and makes them used in unacceptable way, like using them as a storage or to throw garbage instead of keeping them tidy and clean open space. This improper uses and the bad environmental conditions affect negatively the image of the spaces themselves, the image and identity of the downtown and the entire city's image as well.

\section{In-between forgotten spaces improvement framework}

As was mentioned before, the main aim of this study is to enhance the twin cities downtown quality environmentally, socially and functionally by revitalizing the in-between forgotten spaces. In order to do that, there is a need to suggest uses of these spaces and to define short-term, long-term planning and design recommendations.

\subsection{Suggested uses}

According to the problems defined during the fieldwork in the study area, there are some suggested uses to solve and improve the overall condition of the area and to provide services that are presently unavailable there. These are not the only possible uses for the in-between spaces, but they present the most common and affordable uses to revitalize the available and afford acceptable range of practical options. One of the most important steps in this regard is to involve all community groups (public sector, private sector, peoples and voluntary organizations) in these efforts. The cooperation between these groups will lead to successful revitalization process. The public sector will be linking all groups to each other, responsible for emerging of new policies if needed, and making the balance between all parts involved in the process. The private sector will be assisting in taking decisions especially when they are related to financial and funding issues. The people (daily users) and volunteers are the dynamo of the revitalization process, they are the future users of these spaces and the volunteers are the implementation and creative body of the revitalization process. The suggested uses are:

\subsubsection{Shortcut ways}

In the twin cities downtown there is a problem in mobility. They have to go a long way around to reach their destination. This fact causes crowdedness on the 
sidewalks that are not enough to accommodate people's movement. Thus, using the in-between spaces for people's mobility will shorten the walk distances and decrease the conflict between cars and people as is the case in spaces No. 15 and 6 .

\subsubsection{Pocket gardens and public plazas}

Moving through the twin cities downtown visitors strongly feel that they move between a complex of buildings that lacks green and social interaction areas, which force them to move quickly \& uncomfortably. The revitalization of the inbetween spaces as pocket gardens or public plazas for various social and cultural activities will improve the quality of downtown life and increase the social interaction within the downtown community.

\subsubsection{Entertainment and service area}

There is a lack of entertainment and services areas in the twin cities downtown like open restaurants \& cafeterias, safe and comfort stalls area, public bathrooms, and many other needs that are not provided in the downtown. The restaurants and cafeterias available nowadays in the downtown areas are mostly close spaces that have no added value to the citizens, while bathrooms and stalls are totally absent.

\subsection{Planning and design recommendations}

These recommendations include short-term planning recommendations that are to provide a quick reaction towards the present forgotten in-between spaces within the current available possibilities. Long-term planning recommendations they are needed to address future improvements rather than immediate reactions. Urban design recommendations are important to know the needed properties and characteristics of the space. These characteristics are safety, comfort, flexibility, surprising experience and equity.

\subsubsection{Short term planning \& design recommendations}

1. Setting priorities and defining which spaces to be revitalized first.

2. Finding ways to enhance each space components: accessibility, visibility and environmental conditions.

3. Preparing pilot projects to revitalize one or more of the forgotten spaces and to examine the exploitation process in evaluating the outcomes of such pilot interventions to avoid the mistakes in other revitalization projects in future.

\subsubsection{Long term planning and design recommendations}

1. Providing an overall plan to the city showing the locations of these spaces and defines the suitable use of each location.

2. Holding workshops and encourage public participation in order to know their needs and to study the possibilities of intervention.

3. Drafting policies to support flexibility within the revitalized spaces and make special events scheme for them. 
4. Outlining regulations and guidelines for open spaces development in the twin cities.

5. Providing a guidebook to deal with the forgotten spaces.

6. Increasing people's awareness towards these spaces in all stages of work from planning to exploitation.

\subsubsection{Design recommendations}

1. Each shop must provide access to the back space of the building.

2. If the space is invisible an attraction element should be used to inform that there is a space inside.

3. The design elements and must be suitable durable and easy to maintain.

4. There is a minimum amount of green elements (trees, shrubs, etc.) for each space.

\section{Conclusion}

The results of this study show that the forgotten spaces existing in the downtown of Ramallah and Al-Bireh have sufficient area in total and a manageable area for revitalization of each one of them; in addition to that they are well distributed. These spaces are forgotten since the sixties of the $20^{\text {th }}$ century, no body care about their existence or exploitation for the benefit of the local citizens, they have negative effect ono the urban fabric, but still they have great potential for environment improvement within the two cities downtown. The lack of integration between in-door and out-door activities, the enclosure of buildings around spaces, the lack of accessibility and the attitude of people, either owners of land lots or daily users of the city spaces, assisted to the formation of these inbetween forgotten spaces and for present bad condition. But, these spaces could be an important resource to increase the public spaces and everyday life quality within the downtown, but this need drafting of planning and building policies and raising the public awareness, while the two municipalities, preferably in joint efforts propose pilot projects for their revitalization and exploitation.

\section{Acknowledgement}

This paper extended from a master thesis work effort with the Urban Planning and Landscape Architecture Master Program at Birzeit University.

\section{References}

[1] Ryan, G. Raymond and Zoe., Open: New designs for public space. Newyork: Ven Alen institute, 2004.

[2] Chase, John, Crawford, M \& Kaliski, J., Everyday urbanism. The Monacelli press, 2008.

[3] Gehl, J., Life Between Buildings: Using Public Space. Washington DC: Island Press, 2011. 
[4] Campos, B. Life between building: Using public space \& cities for people books review. Sao Paulo: The Journal of space Syntax, 2012.

[5] Lalbakhsh, E., "The Impact of Recycling Urban Space in Sustainable Development in Developing Countries." Sciverse science direct, 2012: pp. 331-334.

[6] Shaw, P., Healey and Tim. "Changing meanings of 'environment' in the British planning system." Transactions of the Institute of British Geographers (Willey blachwell) 19 (1994): pp. 425-438.

[7] Luz, A., "Places In-Between: The Transit(ional) Locations of Nomadic Narratives", 2004.

[8] Moughtin, C., Cuesta, R., Sarris, C., Signoretta, P., Urban design methods and techniques. Elsevier's, 2003.

[9] Muge, A., "New-generation Public Spaces - How 'Inclusive' Are They?" "Open Space: People Space Conference". Edinburgh: The research centre for inclusive access to outdoor environments, 2004.

[10] Giddings, B., Charlton, J. \& Horne, M., "Public squares in European city centres." Urban design International, Macmillan Publishers, 2011: pp. 202-212.

[11] Trancik, R., Finding lost space. John Willey \& Sons, Inc, 1986.

[12] Gieryn, T. F., "A Space for Place in Sociology." Annual Review of Sociology, 2000: vol 26. pp. 463-496.

[13] Lynch, K., Wasting away. Sierra club books, 1990.

[14] Neuman, M., Wasting Away by Kevin Lynch and The Production of Space by Henri Lefebvre. Calefornia: Berkeley Planning Journal, 1992.

[15] Franck, K \& Stevens, Q., Loose space: Possibility and diversity in urban life. London \& Newyork: Taulor \& Francis group, 2007.

[16] Southworth, M., "Wastelands in the Evolving Metropolis." Institute of Urban \& Regional Development, 2001: http://escholarship.org/uc/item/8.

[17] Marini, S., "Returning to Wasting Away" The 4th International Conference of the International Forum on Urbanism (ifou), The New Urban Question - Urbanism beyond Neo-Liberalism . Amsterdam/Delft, 2009.

[18] Shibli, A., "Almanara square: Monumental architecture and power." Jerusalem quarterly, 2006: pp. 52-64.

[19] Qasem, SH., Ghadban, SH. \& Wanan,S., "The emergence of Al-Manara Square as a new center for the twin cities Ramallah and Al-Bireh." Grafima Publications. Skiathos Island, 2013. pp. 1217-1227.

[20] Al-Dajani, A. H., The Twin Cities Ramallah, Al-Bireh \& villages. Jerusalem, 1998. 